Case Report

\title{
Assessment on Effectiveness of On-job Training of Supportive Staffs: The Case Jimma University College of Agriculture and Veterinary Medicine
}

\author{
Teshome Kassa Degu ${ }^{1}$, Kher Deng Tholbok ${ }^{2}$ \\ ${ }^{1}$ Department of Rural Department and Agricultural Extension, College of Agriculture and Veterinary Medicine, Jimma University, Jimma, \\ Ethiopia \\ ${ }^{2}$ Department of Rural Department and Agricultural Extension, College of Agriculture and Natural Resources, Gambella University, Gambella, \\ Ethiopia
}

\section{Email address:}

teshomekassa528@gmail.com (T. K. Degu), dengtholbok@gmail.com (K. D. Tholbok)

\section{To cite this article:}

Teshome Kassa Degu, Kher Deng Tholbok. Assessment on Effectiveness of On-job Training of Supportive Staffs: The Case Jimma University College of Agriculture and Veterinary Medicine. Journal of Human Resource Management. Vol. 4, No. 5, 2019, pp. 76-81.

doi: 10.11648/j.ajmse.20190405.11

Received: September 3, 2019; Accepted: October 31, 2019; Published: November 26, 2019

\begin{abstract}
On-the-job training could be considered as those types of training for employees to assist them develop their skills in particular occupation, vocation or discipline. The main purpose of the study was to assess the effectiveness of on-job training of supportive staff in Jimma University College of Agriculture and Veterinary Medicine. The specific objectives were therefore; first to assess the effectiveness of on-job training on four levels (reactions, learning, behavior and result). Second, to examine factors affecting effectiveness of on-job training. Third, to investigate effects of on-job training on the staffs. The descriptive research design was used for this study. The study utilizes sample of fifty respondents, which selected through simple random sampling method and a semi-structured questionnaire for data collection. The data were analyzed using Kirkpatrick evaluation model and SPSS version twenty software. The result shows some of training challenges such as workload, lack of material access and too short duration for the employee during the on-job training programme.
\end{abstract}

Keywords: On Job Training, Effectiveness, JUCAVM, Staffs

\section{Introduction}

On-the-job training could be considered as those types of training for employees to assist them develop their skills in particular occupation, vocation or discipline. Such types of training normally take place after an individual has begun his work responsibilities. The various forms to which on-the-job training may take encompass workshops, refresher courses, seminars and induction courses [1]. Such training programmes may be strategic to meet a particularly designed strategy, informational to give out particularly new or very important information or operational in order to help explain how particular skills should be operated.

Some scholars [13] explained that training is regarded as one of the most important functions of Human Resource Management (HRM). According to the study [3], poor managerial support or an unfavorable departmental climate could limit the impact of creativity training with regard to influencing idea implementation.

The choice of training methods and programmes is influenced by several factors such as availability of trainer, trainer skills, characteristics of participants, socio-cultural environment, programme objectives, principles of learning, and available infrastructure [2].

Some scholars [12] confirmed that employee motivation plays a key role for effectiveness of training outcomes. Usually, such training programs which are assigned by management, leads to greater employee motivation than those where attendance is optional. Employees take only those 
trainings seriously, where they are clear about the content, objectives and outcomes [11].

Assessing the effectiveness of training means to determine to what extent the undertaken training has led to acquire the required practical skills. Organizations spend an immense amount of time and money on training in order to facilitate employee's learning of job-related competencies [4]. According to a report [7] (Leach and Liu, 2003) to evaluate training investments critically, organizations need to know how reactions, knowledge acquisition, and behaviour change impact outcomes. An organization needs to know the value of measuring training at multiple stages. For instance, the four levels of evaluation, which referred to as the Kirkpatrick Evaluation Model was used to evaluate the effectiveness of training period, introducing four levels or four requirements including reaction, learning, behavior and results of the training. The theory of Donald Kirkpatrick is the standard and professional method to evaluate the result of training for human resource [8]. A study [6] stated that training effectiveness may be assessed by considering the results or evaluation, performance of the trainees and their ability to transfer techniques to their jobs. Training effectiveness can also be a function of trainee characteristics, training design and contextual factors [10].

The failure to consistently find results for the effectiveness of training through the use of behavioral and performance rating criteria can be attributed to several sources, including training design issues, trainee characteristics, work environment characteristics, and criterion issues [5]. To examine training effectiveness using results criteria, the inherent difficulties involved in collecting objective performance measures of trainees [9].

Though various study reports examined the training effectiveness, there is limited determinants that affect training programme in general and on-job training in particular for JUCAVM staffs. Therefore, the purpose of this study was to examine the effectiveness of the on-job training of supportive staff in JUCAVM.

Research question

What factors hinder effectiveness of on-job training?

What is the effectiveness of on-job training on four levels (reactions, learning, behavior and result) there?

What is the effect of on-job training on supportive staffs in JUCAVM?

General objective

To assess the effectiveness of on-job training of supportive staff in JUCAVM

Specific objectives

a. To assess the effectiveness of on-job training on four levels (reactions, learning, behavior and result) in JUCAVM

b. To examine factors affecting the effectiveness of on-job training of the finance and ICT- e-learning staffs in JUCAVM

c. To investigate the effects of on-job training on finance and ICT e-learning supportive staff in JUCAVM

\section{Methodology}

\subsection{Sample Size and Sampling Techniques}

Based on the purpose of the study in assessing the effectiveness of on-job training of the selected staffs, ICT e-learning and finance, 50 respondents who were full-time employees and working on different positions were selected by simple random sampling method from the chosen two staffs with the population of 51 employees in these staffs. Both male and female employees of all age level with their respective experience level were included for the study.

\subsection{Data Collection Methods}

This study was based on both primary and secondary data. Primary data were collected through a semi-structured questionnaire which were administered personally to the two staffs' employees. The questionnaire was prepared to assess the effectiveness of on-job training of the selected JUCAVM's staffs. The secondary data used in the study were also collected from related journals, websites and JUCAVM records.

\subsection{Data Analysis}

Analyses of data were performed using the Statistical Package for Social Sciences (SPSS) software version twenty (20) and Kirkpatrick model.

\section{Result and Discussion}

\subsection{Demographic Characteristics of the Respondents}

The study sought to find out the effectiveness of on-the-job training programme of the two selected staffs, namely, Finance and ICT e-learning employed individuals in JUCAVM. The questionnaires were distributed among subjects. The findings of this study started with the analysis and discussion of data gathered from the sample respondents. At first time the practitioners analyses the biographic data of participants which shows in Table 1 . Out of 50 participants 30 were male and 20 were female. This implies that there was slight variation between male and female in attending the training. Regarding the age of participants, the majority age of participant stood at 26-30 years old (25 participants, 50 per cent) by which majority of human resources from the two staffs were categorized under this age group and expected to be more productive.

Table 1. Biographic characteristics of the respondents $(n=50)$.

\begin{tabular}{lll}
\hline sex & $\mathbf{N}$ & $\mathbf{\%}$ \\
\hline male & 30 & 60.0 \\
female & 20 & 40.0 \\
Total & 50 & 100.0 \\
age & & \\
$20-25$ & 5 & 10.0 \\
$26-30$ & 25 & 50.0 \\
$31-35$ & 10 & 20.0 \\
$36-40$ & 5 & 10.0 \\
$41-45$ & 5 & 10.0 \\
\hline
\end{tabular}




\begin{tabular}{lll}
\hline sex & $\mathbf{N}$ & $\mathbf{\%}$ \\
\hline Total & 50 & 100.0 \\
Education level & & \\
Diploma/10+3 & 20 & 40.0 \\
BSc/BA & 25 & 50.0 \\
MSc/MA & 5 & 10.0 \\
Total & 50 & 100.0 \\
\hline
\end{tabular}

Source: own data, 2019

As to the result, table 1 shows that all employees were categorized according to field of study, experience level and year of experiences. The field of the study of participants was one of the interesting areas in this study. As table 1 showed both staffs finance/accountants and ICT had equal percentage $(50 \%)$ of participantion in each field. It is very interesting to note that inviting of employees to had job-specific training had positive effect on employee's performance. The result also showed that all respondents were permanent in the institute while differing in level of experiences. The frequency table illustrated that 45 participants $(90 \%)$ were senior while the remaining 5 of the participants $(10 \%)$ were junior. Regarding experience, least number of participants had between 11-15 years' experience (20 per cent); majority of participants had experience between 0-5 years ( 40 per cent) and 6-10 years (40) of participants.

\subsection{Evaluation of Training Effectiveness}

This study examined empirically four levels of measuring training effectiveness with the help of a semi-structured questionnaire using a sample of the employees. The theory of Donald Kirkpatrick (four levels of training evaluation) is the standard and professional method to evaluate the result of training for human resource [8]. The result of evaluation analysis specifies that the level extracted in this paper fairly match with the theoretical factors given by Kirkpatrick's model of training. The names of the levels extracted in the analysis were reaction, learning, Behavior and outcome. It can be conducted that Kirkpatrick's model of training evaluation holds fairly well in this context.

The first level focused on employee's reactions to the training programme. For this level, the result in table 3 shows that respondents were forwarded their opinion to reaction on the status of training. In this level, various criterion evaluated based on the developed questionnaire on the availability of the training, accessibility of the training for all employees, frequency of the training, feeling worth, accommodate learning style, level of satisfaction, improved competency and suggestions from the respondents.

A study [13] found that training is regarded as one of the most important functions of Human Resource Management (HRM). The result in the above table 1 shows that majority of respondents $(90 \%)$, said "yes" as the training was accessible and helpful to all employees while justifying it from the frequency, they attend the training. From this reaction, the study result shown in the following figure 1 enabled to evaluate level of satisfaction as the majority of respondents $(60 \%)$ satisfied more and the remaining $40 \%$ of them less satisfied from the given training.

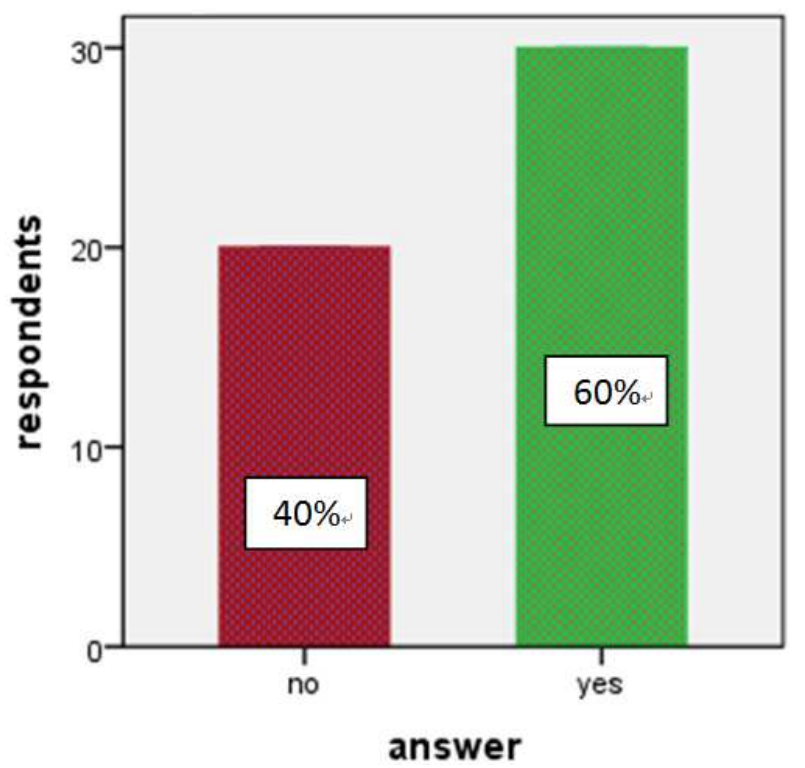

Figure 1. Satisfaction level.

Employees take only those trainings seriously, where they are clear about the content, objectives and outcomes [11]. As to the findings in table 3 illustrates, a larger majority of the respondents, $30(60.0 \%)$ have ever attended on-the-job training three times in the last three years one after the others, representing $10.0 \%$, $20.0 \%, 10.0 \%$ for once, twice and others stated that there was variation among participants in attending the training and satisfied. The respond obtained from the employees shows that 20 percent reacted as the training was not such much worth and time consume while the remaining 80 percent feel worth in that it not consumes resource in terms of time.

The second level focused on learning and skills gained from the training. In this instance, the result in table 4 shows that evaluation of the training from what the respondents learned was crucial on assessing what they apply confidentially and be commitment. The evaluation also attempts to identify changes in knowledge and skill.

According to result of the finding, equal percentage was shared as 30 percent of the respondents develop personal skill and 30 percent of them considered the training as a tool for capacity building. Meanwhile, 20 percent of respondents acquired improved skill, capacity, and well performed knowledge management and customer services skills due to training. Some of respondents $(10 \%)$ got developed some sorts of knowledge management and customer service habit in their actual job.

The status of learning style for employees also helps to know the effectiveness of the training. For instance, the result also shows that 60 percent of respondents answered as the training was under the medium level. This implies that there is still some training gap that needed support or further training programme. From these results, the variation of idea among employees indicates certain job-specific need is expected to be fulfilled through effective training programme. Due to the fact that there was training gap on knowledge management and customer service, further study is needed. 
Table 2. Level-2 evaluation.

\begin{tabular}{lll}
\hline important things learned by respondent & $\mathbf{n}$ & $\mathbf{\%}$ \\
\hline develop personal skill & 15 & 30.0 \\
capacity building & 15 & 30.0 \\
knowledge mgt and customer service & 5 & 10.0 \\
all above & 10 & 20.0 \\
no answer & 5 & 10.0 \\
Total & 50 & 100.0 \\
support needed & & \\
materials & 10 & 20.0 \\
additional training & 15 & 30.0 \\
no answer & 25 & 50.0 \\
Total & 50 & 100.0 \\
Motivation sources & & \\
staff members & 5 & 10.0 \\
manager & 20 & 40.0 \\
by self & 5 & 10.0 \\
all above & 20 & 40.0 \\
Total & 50 & 100.0 \\
\hline
\end{tabular}

Source: own data, 2019

The second level in creating positive attitude among the learners and promote learners' satisfaction. For instance, the frequency distribution result shows that $60 \%$ of sample respondents had satisfactory progress in their learning. Some scholars [12] confirmed that employee motivation plays a key role for effectiveness of training outcomes. Usually, such training programs which are assigned by management, leads to greater employee motivation than those where attendance is optional. Therefore, this study examined the main source of the two staff's motivation and 40 percent of the individuals motivated by the higher manager. This implies that employee motivation had more influence on training effectiveness. They had acknowledged that the level of learning of the training program had improved. The employees had confirmed that, after accomplishing the short-term training course and beginning their professional career in this regard, they would be capable to practical knowledge and apply their special knowledge of their perspective or conveying the knowledge to others.

The third level focused on the changes in the task behavior of employees after attending the training. The study revealed that how well people apply their training and to see changes in knowledge and skill gained and/or new things. Factors of training like wrongs found, challenges and opportunities were the major findings in this level as shown in tables 5 and 6.

Table 3. Level- 3 evaluation.

\begin{tabular}{lll}
\hline Knowledge and skill apply & $\mathbf{n}$ & $\mathbf{\%}$ \\
\hline no & 15 & 30.0 \\
yes & 35 & 70.0 \\
Total & 50 & 100.0 \\
Improve competency & & \\
strongly agree & 15 & 30.0 \\
agree & 25 & 50.0 \\
disagree & 10 & 20.0 \\
Total & 50 & 100.0 \\
\hline
\end{tabular}

Source: own data, 2019

The result in the table 5 helps to see what is change on the trainees because of training. For instance, applying knowledge and skill and improved competency are the major indicators for employee behavior. The respond from the employee approved here by 70 percent said yes while the remaining 30 percent oppose it. In addition, 30 percent of the employee strongly agreed as the training improves their competency very well. Half percent of the respondents (50\%) preferred to say agree in the result since they expect something else to fulfill their need more. However, a few of them $(20 \%)$ completely disagree which indicates less competency improvement so that, there is a need to make a functional training.

Table 4. Factors affect the effectiveness of on-job training methods.

\begin{tabular}{lll}
\hline challenges & $\mathbf{n}$ & $\mathbf{\%}$ \\
\hline lack of material access & 5 & 10.0 \\
work load & 10 & 20.0 \\
no answer & 35 & 70.0 \\
Total & 50 & 100.0 \\
\hline
\end{tabular}

Source: own data, 2019

The choice of training methods and programmes is influenced by several factors such as availability of trainer, trainer skills, characteristics of participants, socio-cultural environment, programme objectives, principles of learning, and available infrastructure [2]. A report [3] also stated that unfavorable environment affects the training effectiveness. Similarly, the result of this case study, table 6 Show that, powerful challenges are almost coming from work load about $10 / 20 \%$ out of the rest. Since the services are for all no one out from their working service, it is difficult to make frequencies on-job training while handling of giving customers services, the others challenges is lack of materials and is a minimum factor, meaning that it is less affecting the effectiveness of on-job training about $5 / 10 \%$ out of the rest.

The fourth level focused on the changes in the functioning of parts or the entire work which have resulted from changes in the task behavior originating in training. As shown in table 7 , result from the study revealed that training programme was helpful, productive and cost effective that is to measure change in the results of the university to ensure the progress made at organizational/institutional level.

Table 5. Level-4 evaluation.

\begin{tabular}{lll}
\hline Training helpful & $\mathbf{n}$ & $\mathbf{\%}$ \\
\hline no & 5 & 10.0 \\
Yes & 45 & 90.0 \\
Total & 50 & 100.0 \\
\hline
\end{tabular}

Source: own data, 2019

The study also attempted to identify some of the variables that help in examining the achieved level of effectiveness. In the findings of the first research question, the average samples of result illustrated that, existence of training courses for employees in the selected staffs had been successful in terms of job-specific skill development, creating positive attitudes and reaction in learners. 
Table 6. Training opportunities.

\begin{tabular}{lll}
\hline Opportunities & $\mathbf{n}$ & $\mathbf{\%}$ \\
\hline effective management & 10 & 20.0 \\
organized training & 15 & 30.0 \\
all above & 15 & 30.0 \\
no answer & 10 & 20.0 \\
Total & 50 & 100.0 \\
\hline
\end{tabular}

Source: own data, 2019

Opportunities are the things that make on-job training more effective to run in the given institution as compared with challenges that hinder the accessibility of on-job training. According to this case, table 8 shown that the organizing and effectiveness of on-job training can be taken as the main indicators of evaluation of whether there is/are opportunities or not in given institution, to consider these two variables organizing of on-job training was the first compared with effective management. This indicate that, there is organizing training, but the question is that "is it effective enough?", therefore according to the result above table $15 / 30 \%$ being organized and $10 / 20 \%$ have been effective managed, therefore the main focus will be on effective management.

The result of factor analysis specifies that the factors extracted in this paper fairly match with the theoretical factors given by Kirkpatrick's model of training which includes reaction, learning, and Behaviour and outcome.

At level 1, most of the respondents were satisfied with the training programs. At level 2, majority of the respondents learned the skills taught. At this phase, the respondents were evaluated on their progress or behavioural changes through testing of knowledge, skills and attitudes acquired. At this stage, evaluation on the way in which knowledge was transferred is being done to ensure the effectiveness of training.

At level 3, the findings reported that the respondents use the new skills on the job but limited to short duration because of workload. This is the measure during performance of job after training to see the usefulness of training objectives, change in behaviour or approach after the training and the evaluation of training method. At level 4, the findings revealed that the training programs was productive and cost effective that is to measure change in the results of the university to ensure the progress made at organizational/institutional level.

\section{Conclusion and Recommendation}

It can be concluded that Kirkpatrick's model of training evaluation holds fairly well in this context. This manifest itself in the positive responses of the trainees, from the various aspects of on-the job training programs and the relevant information of the given programme. In addition, the factors affect on-the-job training programme, trainees' job behavior, obtaining job-specific personal skills as well as training opportunities were assessed. The study intended to assess the effectiveness of on the job training programme on the employee performance for the Finance and ICT e-learning in the JUCAVM.
Though the results show that on-job training were effective at both staffs, there were experienced some challenges during the process of implementing the on-job training programme. These includes: workload and lack of material access, too short duration for the training. The work overload challenge was more powerful than that of others for the trainees and hence it is difficult in attending and managing of their work as well as further personal skill development.

As the result indicated some challenges (workload, lack of material and effective management), it is recommended that job-specific training should be given in multi-dimensional process. In addition, lack of material access should be ensured to facilitate the appropriate material for effective training programme.

Suggestion for Future Research

It is suggested that future research should be undertaken to expand this study to all groups of staff departments in JUCAVM; therefore, there is a need for future studies to deep empirical research to know other factors that predict and affects training programme. Future study should focus to examine the institutional commitment and motivation levels of employees to the training programmes as they are the main assets of the institution. Motivating them can be beneficial to upgrade their knowledge and skills which in turn be used to improve the position of the institution.

\section{Acknowledgements}

We would like to acknowledge all the previous investigators who provide valuable research articles.

\section{Conflict of Interest}

All authors declared that there is no conflict of interest.

\section{References}

[1] Ackummey, M. A., Boison, G. A., Hama, J., Kankam, G., Ohene-Darko, Owusu-Mensah, F.\& Quist, F. (2001). Education and culture, I. E. D. E. Winneba: University of Education.

[2] Agarwala, T. (2007). Strategic Human Resources Management. Oxford University Press. India.

[3] Birdi, K. S. (2005). "No Idea? Evaluating the Effectiveness of Creativity Training", Journal of European Industrial Training, 29 (2), pp. 102-111.

[4] Casio, W. F., (2000). Costing Human Resources: The Financial Impact of Behavior in Organizations, (4th ed.), Cincinnati OH: South-Western.

[5] Goldstein, I. L. (1986). Training in Organizations: Needs assessment, development and evaluation. Monetery, CA: Brooks/Cole. Quoted in Ostroff Cheri (1991), Training Effectiveness measures and scoring schemes: A comparison, Personnel Psychology, pp 353- 374.

[6] Huque, A. S and Vyas, L. (2008). Expectations and performance: assessment of public service training in Hong Kong. The International Journal of Human Resource Management. 19 (1), pp 188-204. 
[7] Leach, P. M. and Liu, H. A. (2003). Investigating interrelations among sales training evaluations. Journal of Personal Selling and Sales Management. 22 (4), pp 327-339.

[8] Nickols, F. W. (2005). Why a stakeholder approach to evaluating training, Advances in Developing Human Resources. 7, pp 121-134.

[9] Ostroff, Ch. (1991). Training Effectiveness measures and scoring schemes: A comparison, Personnel Psychology, pp 353- 374 .

[10] Scaduto, A., Lindsay, D., and Chiabur, S. D. (2008). Leader influences on training effectiveness: motivation and outcome expectation process, International Journal of Training and Development. 12 (3), pp 158-170.
[11] Tai, W. (2004). Effects of Training framing, general self-efficacy and training motivation on trainee's training effectiveness', Personnel review, 35 (1), pp. 51-65.

[12] Tsai, W. C., and Tai, W. T. (2003). Perceived importance as a mediator of the relationship between training assignment and training motivation. Personnel Review. 32 (2). pp. 151-163.

[13] Weil, A., and Woodall, J. (2005). Human Resource Development in France: the corporate perspective, Journal of European Industrial Training, 29 (7), 529-540, https://doi.org/10.1108/03090590510621036. 